\title{
Accuracy assessment of Precise Point Positioning with multi- constellation GNSS data under ionospheric scintillation effects
}

\author{
Haroldo Antonio Marques ${ }^{1, *}$, Heloísa Alves Silva Marques ${ }^{1}$, Marcio Aquino ${ }^{2}$, Sreeja Vadakke Veettil ${ }^{2}$ \\ and João Francisco Galera Monico ${ }^{3}$ \\ ${ }^{1}$ Military Institute of Engineering (IME), Cartography Engineering Section, Rio de Janeiro, Brazil \\ 2 Nottingham Geospatial Institute (NGI), University of Nottingham, Nottingham, UK \\ ${ }^{3}$ São Paulo State University (UNESP), Department of Cartography, P. Prudente, Sp são paulo, Brazil
}

Received 15 April 2017 / Accepted 6 December 2017

\begin{abstract}
GPS and GLONASS are currently the Global Navigation Satellite Systems (GNSS) with full operational capacity. The integration of GPS, GLONASS and future GNSS constellations can provide better accuracy and more reliability in geodetic positioning, in particular for kinematic Precise Point Positioning (PPP), where the satellite geometry is considered a limiting factor to achieve centimeter accuracy. The satellite geometry can change suddenly in kinematic positioning in urban areas or under conditions of strong atmospheric effects such as for instance ionospheric scintillation that may degrade satellite signal quality, causing cycle slips and even loss of lock. Scintillation is caused by small scale irregularities in the ionosphere and is characterized by rapid changes in amplitude and phase of the signal, which are more severe in equatorial and high latitudes geomagnetic regions. In this work, geodetic positioning through the PPP method was evaluated with integrated GPS and GLONASS data collected in the equatorial region under varied scintillation conditions. The GNSS data were processed in kinematic PPP mode and the analyses show accuracy improvements of up to $60 \%$ under conditions of strong scintillation when using multiconstellation data instead of GPS data alone. The concepts and analyses related to the ionospheric scintillation effects, the mathematical model involved in PPP with GPS and GLONASS data integration as well as accuracy assessment with data collected under ionospheric scintillation effects are presented.
\end{abstract}

Keywords: Ionospheric scintillation / Precise Point Positioning / GNSS data integration

\section{Introduction}

Global Navigation Satellite Systems (GNSS) are widely used nowadays for geodetic positioning, atmospheric monitoring, navigation and in scientific research, among many other activities. Current systems include GPS, GLONASS, Galileo, BEIDOU/COMPASS, as well as Augmentation Systems such as European Geostationary Navigation Overlay Service (EGNOS) and Wide Area Augmentation System (WAAS) aimed at improving accuracy, availability and integrity. GPS is the most used GNSS, since it has been fully operational for more than two decades now. Nevertheless, GLONASS is also currently a fully operational system with a complete satellite constellation (GLONASS, 2016).

The differences between GPS and GLONASS are well disseminated in the literature and the most important of them is related to the signal transmission, with GPS using Code

\footnotetext{
*Corresponding author: haroldoh2o@gmail.com
}

Division Multiple Access (CDMA) and GLONASS using Frequency Division Multiple Access (FDMA). However, in an ongoing modernization process, the GLONASS satellites are also transmitting signals based on the CDMA technique, starting with the launch of GLONASS-K satellites (Oleynik, 2012; GLONASS, 2016).

Concerning geodetic positioning, special attention has been given in recent years to Precise Point Positioning (PPP) that unlike relative positioning allows position estimation based on a single user receiver. To achieve positioning with centimeter accuracy, the PPP method requires the precise orbits, satellite clock corrections and mathematical modelling for practically all involved effects, either those related with signal propagation or the geodynamic effects affecting the terrestrial stations (Seeber, 2003; Leick, 2004; Hofmann-Wellenhof et al., 2008; Marques et al., 2016). PPP state of the art takes into account the ambiguity resolution, either in real time or in the post processing mode, which has been the motivation for several investigations in recent years, as for example in Ge et al. (2005); Collins \& Bisnath (2008); Laurichesse et al. (2009); Geng et al. (2010); Teunissen \& Khodabandeh (2015). 
The estimated parameters in PPP data processing are, in general, tridimensional coordinates, receiver clock error, tropospheric effects and carrier phase ambiguity for each satellite being tracked. In particular for kinematic trajectories, PPP is strongly influenced by the geometry of the satellite constellation being tracked. The effect of the geometry can be measured by the Dilution of Precision (DOP) parameter, which is strongly related with the number and spatial distribution of satellites. Kinematic positioning is in general degraded when a small number of satellites is available, which frequently occurs in urban trajectories or under severe atmospheric conditions, as for example, under ionospheric scintillation effects.

Scintillation effects are more intense in geomagnetic equatorial and high latitude regions where the occurrences are mostly related respectively to the equatorial anomaly and geomagnetic storms. Scintillation is caused by small scale irregularities in the ionosphere and is characterized by rapid changes in the amplitude and phase of signal, sometimes leading to phase cycle slips and even signal loss of lock. For GPS, the L2 signal (1227.6 MHz) is generally more affected and losses of signal in the L2 can cause problems when applying the ionosphere free combination (ion-free) that is generally used in PPP. Therefore, it is expected that under such conditions the addition of GLONASS data in the position estimation can improve the satellite geometry and consequently considerably improve positioning accuracy.

Several research works have attempted to counter ionospheric scintillation effects on positioning accuracy, where the following can be cited: Conker et al. (2003) that investigate the effect of scintillation on the availability of GPS and SBAS; Aquino et al. (2009) and Silva et al. (2010) that discuss the least squares stochastic model based on signal tracking variances estimated by the models proposed in Conker et al. (2003), respectively, for relative and absolute positioning aiming to mitigate ionospheric scintillation effects; Xu et al. (2012) that present analyses of PPP under strong ionospheric scintillation conditions and shows that the largest PPP error can increase to more than $34 \mathrm{~cm}$ and $20 \mathrm{~cm}$, respectively for the vertical and horizontal components; Marques et al. (2016) that show the performance of GPS L2C signal under varied ionospheric scintillation conditions and Zhang et al. (2014) that propose an adaptive and iterative Kalman filter and quality control for rejecting observables affected by scintillation. The accuracy of the estimated position through PPP can be significantly degraded under scintillation conditions, especially in the kinematic mode. This is due to the weakening of the GNSS signal caused by scintillation effects that may lead to cycle slips and even total loss of lock. In the traditional PPP processing, i.e. without scintillation based stochastic modelling or adaptive process, the ambiguity parameter is reinitialized when a phase jump is detected, in general, by relaxing the state covariance matrix of the Kalman filter. When several satellites are affected, such strategy can cause jumps in the coordinates' time series. The strategy of taking the affected satellite out of the processing works well when there are enough satellites in view at the specific epoch of processing, which is not always the case for kinematic situations under conditions of bad geometry. In this article, the impact of introducing data from a new constellation in the traditional kinematic PPP is analysed, considering data under moderate to strong scintillation conditions. The methodology involved in PPP with GPS and GLONASS integration, including analysis of the impact of scintillation on GPS and GLONASS signals and also accuracy assessment with data collected under scintillation effects is described.

The data were collected by Septentrio-PolaRxS-PRO receivers belonging to the ionospheric scintillation monitoring network deployed in Brazil as part of the EC funded CIGALA and CALIBRA projects (Vani et al., 2016). These receivers collect GNSS data, as well as the well-known scintillation indices S4 and $\sigma_{\varphi}$, commonly used to characterize, respectively, amplitude and phase scintillation effects (Davies, 1990; Van Dierendonck et al., 1993). The data was processed by using the CSRS-PPP software licensed by Natural Resources Canada (NRCAN) for in-house purposes. This article presents the mathematical model involved in PPP with GPS/GLONASS integration, the characterization of ionospheric scintillation through the $\mathrm{S} 4$ and $\sigma_{\varphi}$ indices, as well as PPP accuracy analyses by using GPS data alone and the integration of GPS and GLONASS data collected under ionospheric scintillation effects.

\section{Bibliography review}

\subsection{PPP functional model for GPS and GLONASS integration}

Concerning the PPP method, the pseudorange $(P)$ and carrier phase equations $(\varphi)$ (in meters) for GPS $(G)$ and GLONASS $(R)$ at frequency $\left(f_{i}\right)$ in the Li band can be written as (Leick, 2004; Hofmann-Wellenhof et al., 2008; Cai \& Gao, 2007):

$$
\begin{aligned}
P_{\mathrm{Li}}^{G} & =\rho^{G}+c\left(\delta t_{\mathrm{rec}}^{G}-\delta t_{\mathrm{sat}}^{G}\right)+\delta I_{\mathrm{Li}}^{G}+\delta T^{G}+\mathrm{Orb}^{G}+\delta m^{G} \\
& +{ }_{P_{\mathrm{Li}}^{G}} \cdot \\
& \varphi_{\mathrm{Li}}^{G}=\rho^{G}+c\left(\delta t_{\mathrm{rec}}^{G}-\delta t_{\mathrm{sat}}^{G}\right)-\delta I_{\mathrm{Li}}^{G}+\delta T^{G}+\mathrm{Orb}^{G}+\delta m^{G} \\
& +\lambda_{\mathrm{Li}}^{G}\left(\varphi_{t}^{S}\left(t_{0}\right)-\varphi_{r}\left(t_{0}\right)\right)^{G}+\lambda_{\mathrm{Li}}^{G} N_{\mathrm{Li}}^{G}+\lambda_{\mathrm{Li} \varphi_{\mathrm{Li}}^{G} \cdot}^{G} \\
& \\
P_{\mathrm{Li}}^{R} & =\rho^{R}+c\left(\delta t_{\mathrm{rec}}^{R}-\delta t_{\mathrm{sat}}^{R}\right)+\delta I_{\mathrm{Li}}^{R}+\delta T^{R}+\mathrm{Orb}^{R}+\delta m^{R} \\
& +{ }_{\mathrm{Li}}^{R} \cdot \\
\varphi_{\mathrm{Li}}^{R} & =\rho^{R}+c\left(\delta t_{\mathrm{rec}}^{R}-\delta t_{\mathrm{sat}}^{R}\right)-\delta I_{\mathrm{Li}}^{R}+\delta T^{R}+\mathrm{Orb}^{R}+\delta m^{R} \\
& +\lambda_{\mathrm{Li}}^{R}\left(\varphi_{t}^{S}\left(t_{0}\right)-\varphi_{r}\left(t_{0}\right)\right)^{R}+\lambda_{\mathrm{Li}}^{R} N_{\mathrm{Li}}^{R}+\lambda_{\mathrm{Li} \varphi_{\mathrm{Li}}^{R},}
\end{aligned}
$$

where $\rho^{s}$ ( $s=G$ or $s=R$, respectively, for GPS and GLONASS satellites) represents the geometric distance between satellite " $s$ " and receiver "rec"; $c$ is the speed of light in vacuum; $\delta t_{\text {rec }}^{s}$ and $\delta t_{\text {sat }}^{s}$ are, respectively, receiver and satellite clock errors; $\delta I_{\text {rec }}^{S}$ is the delay caused by the ionosphere; $\delta T_{\text {rec }}^{S}$ is the tropospheric delay error; $\mathrm{Orb}^{s}$ is the error due to imperfections in the satellite orbit determination; $\delta m^{s}$ represents the multipath effect; $\varphi_{t}^{s}\left(t_{0}\right)$ and $\varphi_{\text {rec }}\left(t_{0}\right)$ are the initial phase at time $t_{0}$ respectively for satellite and receiver; $N_{\text {rec }}^{s}$ is the phase ambiguity bias and $\epsilon$ represents the unmodeled errors for either pseudorange or phase. 
When combining GPS and GLONASS data in the positioning adjustment, special attention must be given to the signal structure and its characteristics for each navigation system. Originally, two carrier signals in the L band are disseminated and modulated by two binary codes and navigation messages. GLONASS transmits its signals in different frequencies by using the FDMA technique, while GPS applies CDMA, currently transmitting data centered at frequencies L1, L2 and L5 (Hofmann-Wellenhof et al., 2008; ICD-GLONASS, 2008). However GLONASS is also currently transmitting data by using the CDMA technique on L3 (centered at $1202.025 \mathrm{MHz}$ ), starting with the launch of satellite GLONASS-K in the year 2011, which is part of their modernization process and will facilitate interoperability with GPS and Galileo (Oleynik, 2012).

When applying precise orbits in the PPP processing the solutions with GPS and GLONASS data integration can be referred to the International Terrestrial Reference Frame (ITRF). Therefore, when applying broadcast orbits it is necessary to make the geodetic reference systems, i.e. WGS84 for GPS and PZ90 for GLONASS, compatible. The receiver clock errors are represented by $\delta t_{\text {rec }}^{G}$ and $\delta t_{\text {rec }}^{R}$, while the satellite clock errors by $\delta t_{\text {sat }}^{G}$ and $\delta t_{\text {sat }}^{R}$, respectively, for GPS and GLONASS. The clock errors are given in relation to the corresponding system time, i.e. GPS and GLONASS time, respectively, requiring the adoption of a common time system, normally GPS time. The clock error solution is given by the introduction of the unknown parameter $\left(\delta t_{\mathrm{sys}}\right)$ that can be written as (Cai \& Gao, 2007):

$$
\delta t_{\mathrm{rec}}=t-t_{\mathrm{sys}}
$$

where $t_{\mathrm{sys}}$ is the GPS system time ( $\left.t_{\mathrm{GPS}}\right)$, for GPS observables, or the GLONASS time ( $t_{\text {GLONASS }}$ ), for GLONASS observables. Since the clock error is related to its own system time, the PPP processing with data integration includes the estimation of two receiver clock parameters. The GLONASS receiver clock error and its relation with GPS time can be written as (Cai \& Gao, 2007):

$$
\begin{aligned}
\delta t_{\mathrm{rec}}^{R} & =t-t_{\mathrm{GLONASS}}=\underbrace{t-t_{\mathrm{GPS}}}_{\delta t_{\mathrm{rec}}^{G}}+t_{\mathrm{GPS}} \underbrace{-t_{\mathrm{GLONASS}}}_{\delta t_{\mathrm{sys}}} \\
& =\delta t_{\mathrm{rec}}^{G}+\delta t_{\mathrm{sys}},
\end{aligned}
$$

that is a function of the receiver clock error for GPS and the difference between the GPS and GLONASS system times.

Applying equation (6) in equations 1-4 yields the following results for GLONASS:

$$
\begin{aligned}
P_{\mathrm{Li}}^{R} & =\rho^{R}+c(\underbrace{t_{\mathrm{rec}}}_{\delta_{\mathrm{rec}}^{G}+\delta t_{\mathrm{sys}}^{R}}-\delta t_{\mathrm{sat}}^{R})+\delta I_{\mathrm{Li}}^{R}+\delta T^{R}+\mathrm{Orb}^{R} \\
& +\delta m^{R}+{ }_{P_{\mathrm{Li}}^{R} .} \\
\phi_{L i}^{R} & =\rho^{R}+c(\underbrace{\delta t_{\text {rec }}^{R}}_{t_{\text {rec }}^{G}+\delta t_{s y s}^{R}}-\delta t_{\text {sat }}^{R})-\delta I_{L i}^{R}+\delta T^{R}+\mathrm{Orb}^{R} \\
& +\delta m^{R}+\lambda_{L i}^{R} N_{L i}^{R}+\lambda_{L i \phi_{L i}^{R} .}^{R} .
\end{aligned}
$$

The inter-frequency bias must also be accounted for in the above equations and this is described by Wanninger (2011) and Cai \& Gao (2013). Based on the equations presented in this section and other considerations that are out of the scope of this paper, one can estimate the receiver clock error for GPS $\left(\delta t_{\text {rec }}^{G}\right)$, the time system difference $\left(\delta t_{\mathrm{sys}}\right)$, carrier phase ambiguities for each satellite, tropospheric effects and the coordinates of the station. The first order ionospheric delay can be corrected by applying the ionospheric free linear combination or by the use of Global Ionosphere Maps, or any other ionospheric model such as the Klobuchar model (Klobuchar, 1976) in case only single frequency data are available. The absolute positioning mathematical model with signal integration taking into account multiple GNSS constellations, e.g.: GPS, GLONASS, Galileo and BEIDOU, can be found, for instance, in Li et al. (2015).

\section{2 lonospheric scintillation effects}

Scintillation is characterized by rapid variations in the amplitude and phase of the GNSS signal and is caused by small scale irregularities in the ionosphere. The occurrence of scintillation is intense in the geomagnetic equatorial and high latitudes regions, in particular during solar maxima (Fig. 1). Concerning the equatorial regions, scintillation occurrence is associated with the crests of the equatorial anomaly (centered approximately $15^{\circ}$ in latitude on either side of the geomagnetic equator), where plasma bubbles can frequently appear, leading to the generation of irregularities that may cause scintillation. On the other hand, in the high latitude regions, scintillation occurrence is more frequently related with geomagnetic storms that are associated with solar flares, coronal mass ejections and coronal holes. Figure 1 shows the morphology of scintillation occurrence (Davies, 1990; Basu \& Groves, 2001; Conker et al., 2003).

Scintillation can be monitored through the amplitude and phase scintillation indices, respectively $\mathrm{S} 4$ and $\sigma_{\varphi}$. The S4 index can be computed from the satellite signal power or signal intensity (SI) tracked by the receiver and can be interpreted as a normalized standard deviation around the intensity average. The S4 index can be computed through the following equation (Van Dierendonck, 2001):

$$
S 4=\sqrt{\frac{E\left\{\mathrm{SI}^{2}\right\}-E\{\mathrm{SI}\}^{2}}{E\{\mathrm{SI}\}^{2}}},
$$

where SI is the intensity of the received satellite signal, $E\{$. represents the mathematical expectation (average) over a determined interval, as for example, $60 \mathrm{~s}$ for a sampling rate of $50 \mathrm{~Hz}$.

The phase scintillation index, $\sigma_{\varphi}$, is the standard deviation (in radians) of the carrier phase, and is averaged over intervals of $1,3,10,30$ and $60 \mathrm{~s}$, based on $50 \mathrm{~Hz}$ measurements made over every $1 \mathrm{~min}$ (Van Dierendonck, 2001). Most researchers use the $60 \mathrm{~s}$ version of $\sigma_{\varphi}$, also referred to as Phi60, for analysis. The Phi60 index is given by the standard deviation of the 3000 values of the carrier phase measured at the input of the receiver Phase Locked Loop during the 1 min of reference, and therefore contains the whole frequency range of the spectrum of the phase measurements for that period of time (Aquino 


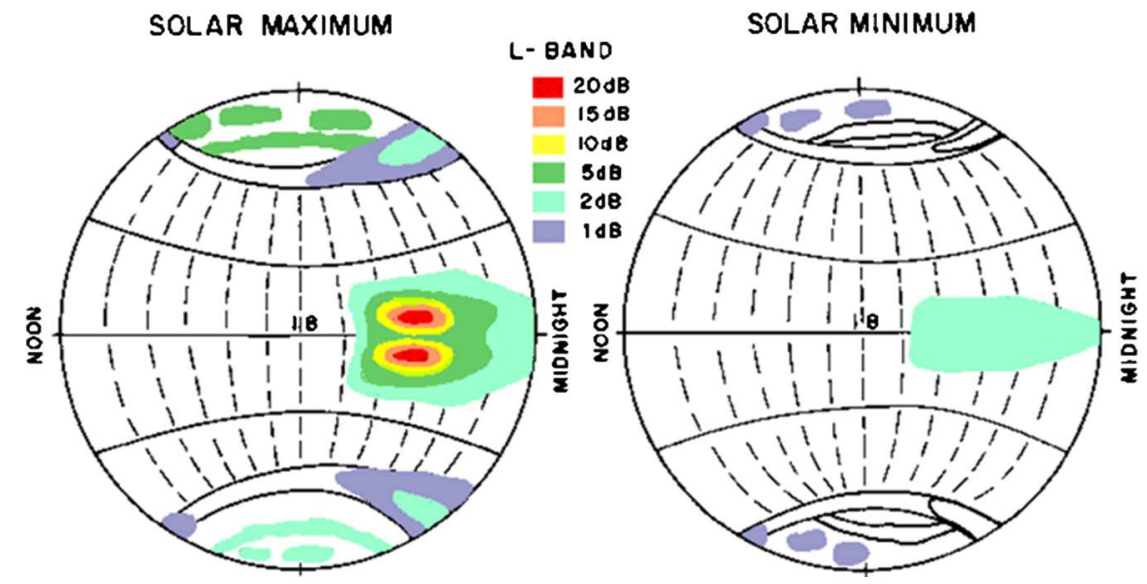

Fig. 1. Geographic regions of scintillation occurrence (Basu and Groves, 2001).

Table 1. Classification of the ionosphere scintillation severity.

\begin{tabular}{ll}
\hline Classification & Index \\
\hline Strong & $(S 4>1.0$ or Phi60 $>0.8)$ \\
Moderate & $(0.5 \leq S 4 \leq 1.0$ or $0.4 \leq$ Phi60 $\leq 0.8)$ \\
Weak & $(S 4<0.5$ or Phi60 $<0.4)$ \\
\hline
\end{tabular}

et al., 2007). It is common practice to use the Phi60 and S4 indices to classify ionospheric scintillation severity as weak, moderate or strong, for example as shown in Table 1 (Tiwari et al., 2011):

These indices are normally computed and recorded by specialized GNSS receivers that are capable to collect GNSS high rate raw data (e.g. at $50 \mathrm{~Hz}$ ) and which normally also compute additional ionospheric parameters such as Total Electron Content (TEC) values. These receivers are generally referred to as Ionospheric Scintillation Monitoring Receivers (ISMR) and can nowadays be found in dedicated monitoring sites around the world, as for example at the GPS Scintillation Monitors (SCINTMON) network in operation over the Brazilian territory (De et al., 2007) or at the CIGALA/ CALIBRA network, also deployed in Brazil (Vani et al., 2016). The experiments described hereafter are based on the use of data recorded by these specialized receivers, and results and analysis are presented in the next section.

\section{Experiments, results and analyses}

The experiments were carried out by utilizing GNSS data from ISMR stations PRU1, PRU2 and PALM that belong to the CIGALA/CALIBRA network in Brazil (Fig. 2), considering a number of days in the years 2011, 2012 and 2013. The days were chosen based on the observed ionospheric scintillation severity, as characterized by the S4 and Phi60 indices (Table 1). The PPP processing was accomplished through the "CSRS-PPP" software from NRCAN either applying the online tool or the version provided directly by NRCAN with the source code of the software licensed for inhouse purposes (Donahue et al., 2015). The CSRS-PPP is

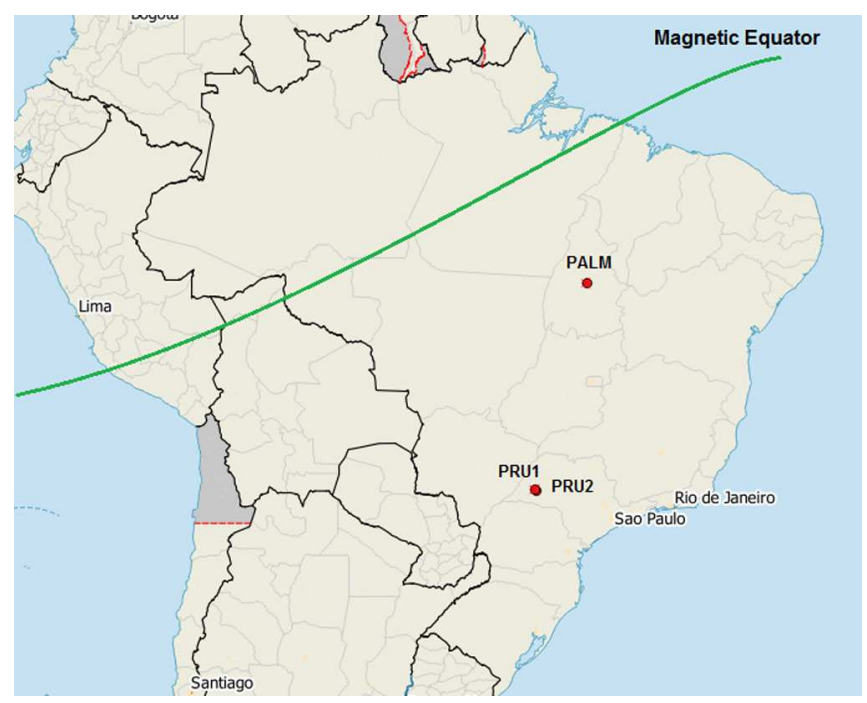

Fig. 2. Stations used in the experiments.

capable of processing GPS and GLONASS data in the static and kinematic PPP modes, applying the ionospheric free linear combination when dual frequency data is available, which allows eliminating the first order ionospheric error. The higher order ionospheric effects (second and third order), depending on the geomagnetic field and electron density can be eliminated through mathematical models and by using information from the International Geomagnetic Reference Field (Bassiri \& Hajj, 1993; Kedar et al., 2003; Fritsche et al., 2005; Hoque \& Jakowski, 2007; Hernandes-Pajares et al., 2007; Marques et al., 2011; Zhimin et al., 2016). The CSRSPPP computes the higher order ionospheric effects based on equations described in the IERS2010 Conventions (Petit \& Luzum, 2010). The troposphere is modeled through the estimation of the Zenithal Wet Delay (ZWD) component as a random walk process while the Zenithal Hydrostatic Delay can be computed from mathematical models, as for example, the Saastamoinen or Hopfield models. The software also allows correcting for Ocean Tide Loading, Earth Body Tide, Phase Center Variation of receiver and satellites, phase windup, 

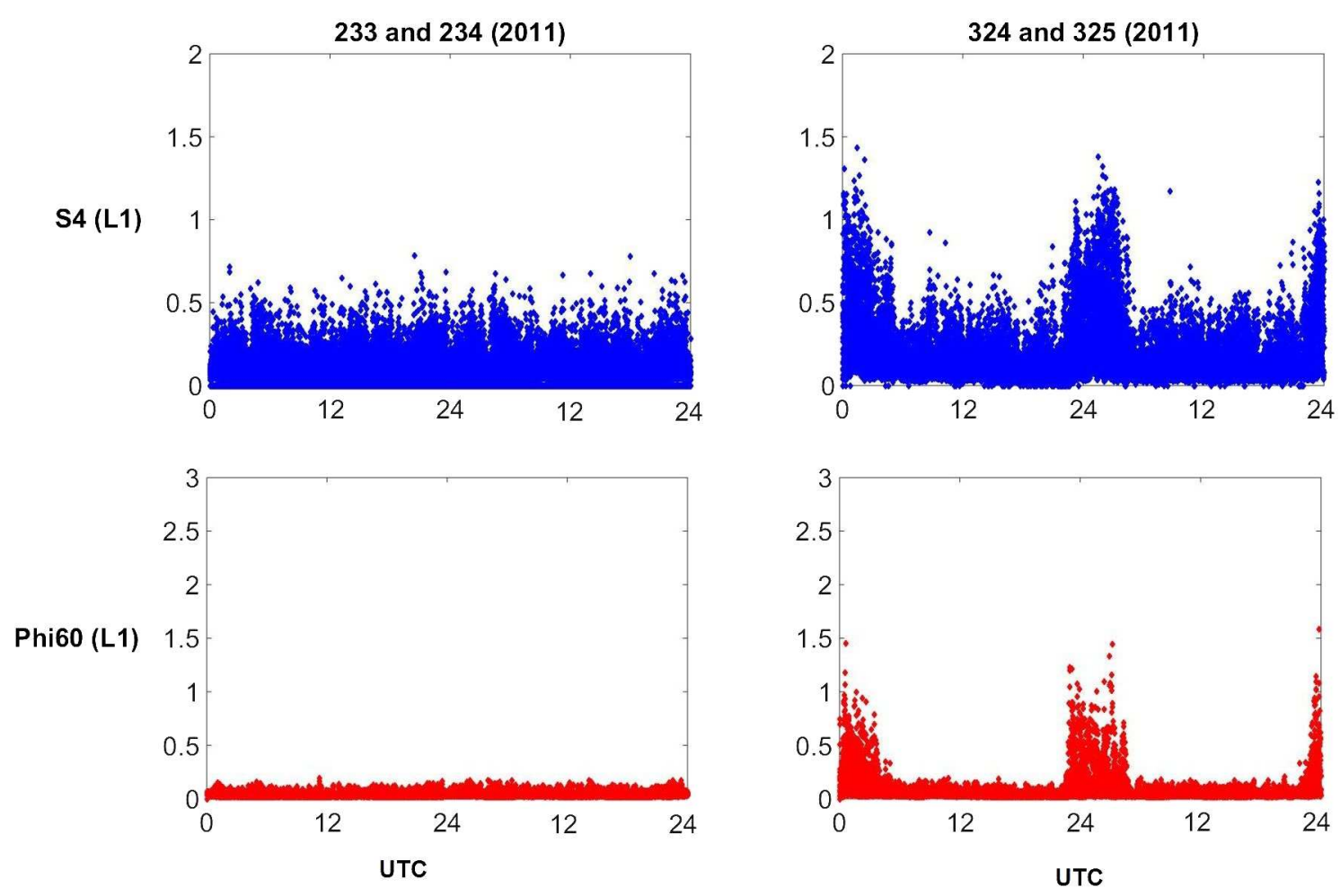

Fig. 3. S4 and Phi60 (GPS - L1) for PRU2 station (DoY: 233-234 and 324-325).

among many other corrections relevant to PPP. The coordinates are represented in the ITRF.

The data were processed considering a satellite elevation mask of $10^{\circ}$, final precise orbits and clocks from the International GNSS Service, with the ZWD estimated as a random walk process $(5 \mathrm{~mm} / \mathrm{h})$. The precisions (standard deviation) of $1 \mathrm{~m}$ and $0.01 \mathrm{~m}$, were assumed, respectively for the ionospheric free code and phase observables. The adopted processing strategy was to first process GPS data alone, and then the integrated GPS and GLONASS data (GPS/GLONASS). The RINEX files were edited with the "teqc" software available from UNAVCO's homepage (https://www.unavco. org/software/data-processing/teqc/teqc.html). Although the data was collected in static mode, the processing was carried out in kinematic mode for both the GPS and GPS/GLONASS solutions. The results were compared to known station coordinates used as ground truth, allowing to refer to the differences as "errors".

As documented in the literature (Kelley, 1989) the occurrence of ionospheric scintillation at equatorial latitudes in general starts after local sunset, approximately at 21:00 UTC (18:00 LT), and affects the GNSS signals until around 03:00 LT in the morning (06:00 UTC) of the next day. Strong scintillation can impact negatively the estimated position, in particular in kinematic surveying, and especially in real time. The first experiment involved GNSS data from PRU2 station considering two pairs of consecutive days in the year 2011. The first pair refers to days 21 and 22 of August 2011 (DoY 233-234), when weak scintillation was predominant, and the second pair refers to 21 and 22 of November 2011 (DoY 324$325)$, which presented periods of strong scintillation ( $\mathrm{S} 4 \geq 1$ ).
Figure 3 shows the S4 and Phi60 values computed for the GPS L1 frequency during the days of the experiments.

According to Table 1, the first pair of days (233-234) represents mostly a weak scintillation period, whereas the second pair (324-325) experienced some strong scintillation effects, particularly in the period of 23:00 UTC of day 324 until 06:00 UTC the next day. The Vertical TEC (VTEC) distribution over South America is shown in Figures 4 and 5, repectively for days 233-234 and 324-325. The plots of VTEC were obtained from La Plata Ionospheric Model (LPIM) Regional Ionospheric Maps available in the context of the Geocentric Reference System for the Americas (SIRGAS) project (http://www.sirgas.org/index.php?id=155\&L=2) (Brunini et al., 2008).

It can be seen in Figure 4 that the VTEC distribution for days 233-234 of 2011 is typical of a quiet ionosphere, with low VTEC values and mostly smooth gradients. This is in total contrast with Figure 5, for days 324-325, when much more intense ionospheric activity is present, with sharp gradients being observed and VTEC values reaching peaks of up to 80 TECU.

The activity starts to increase at around 13:00 UTC on day 324 and continues until around 06:00 UTC the next day. From around 20:00/21:00 UTC on day 324 the effects of the equatorial anomaly can be clearly seen in the plots of Figure 5, with the characteristic double peak in the TEC distribution. The sharp gradients existing between the crests and trough of the TEC distribution provide the favorable conditions for the generation of irregularities that cause scintillation.

The uncalibrated Slant TEC (STEC) for all satellites being observed over the PRU2 station can be seen in Figure 6. The 
H.A. Marques et al.: J. Space Weather Space Clim. 2018, 8, A15

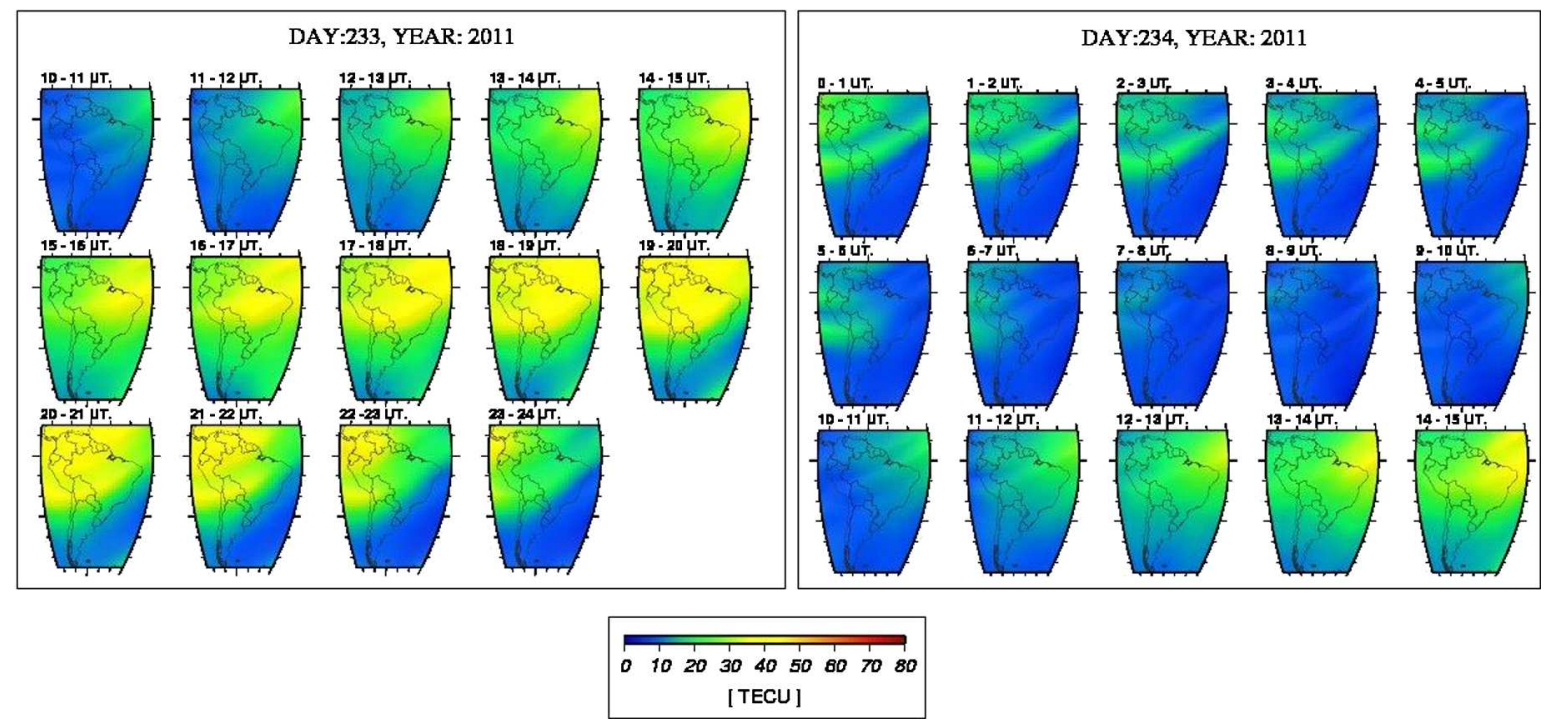

Fig. 4. VTEC distribution for days 233-234 of 2011.

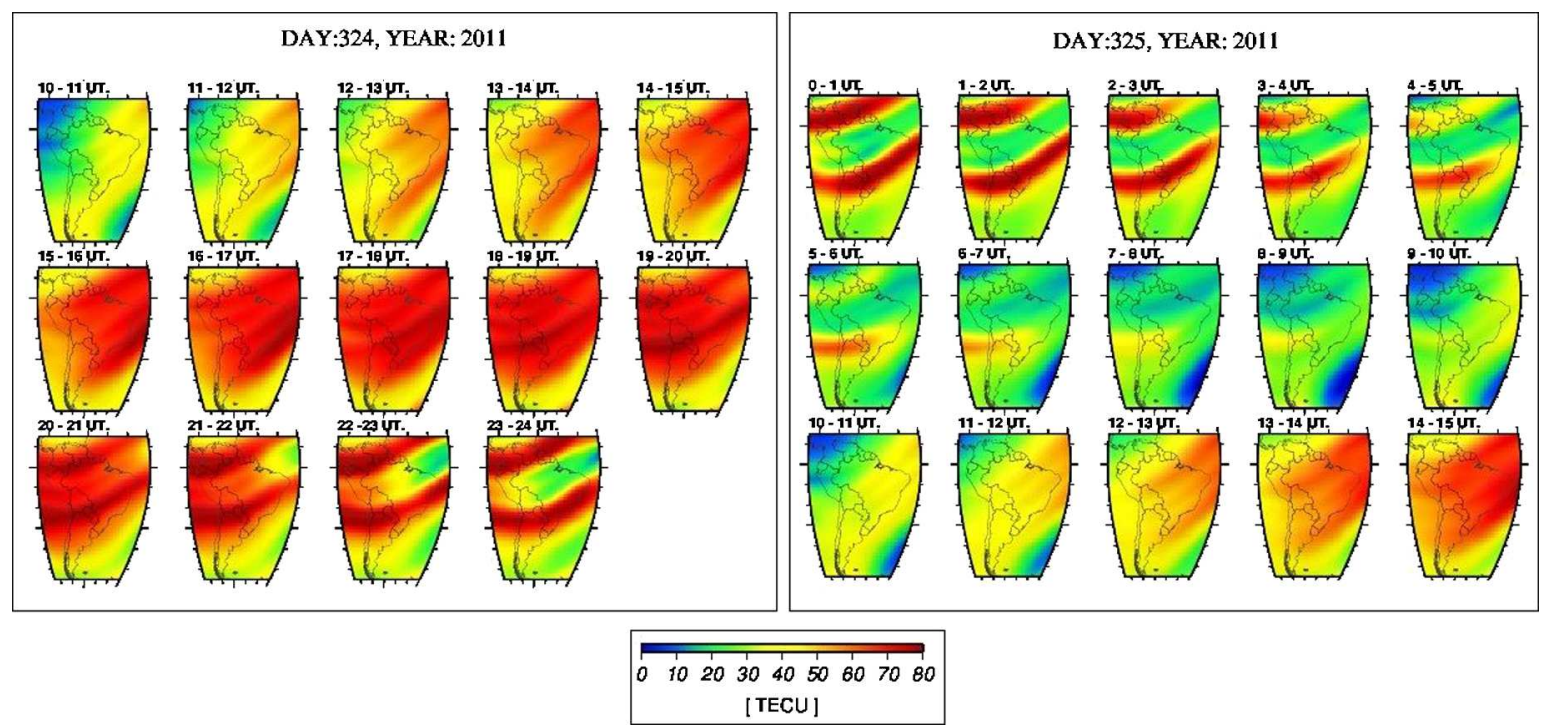

Fig. 5. VTEC distribution for days 324-325 of 2011.
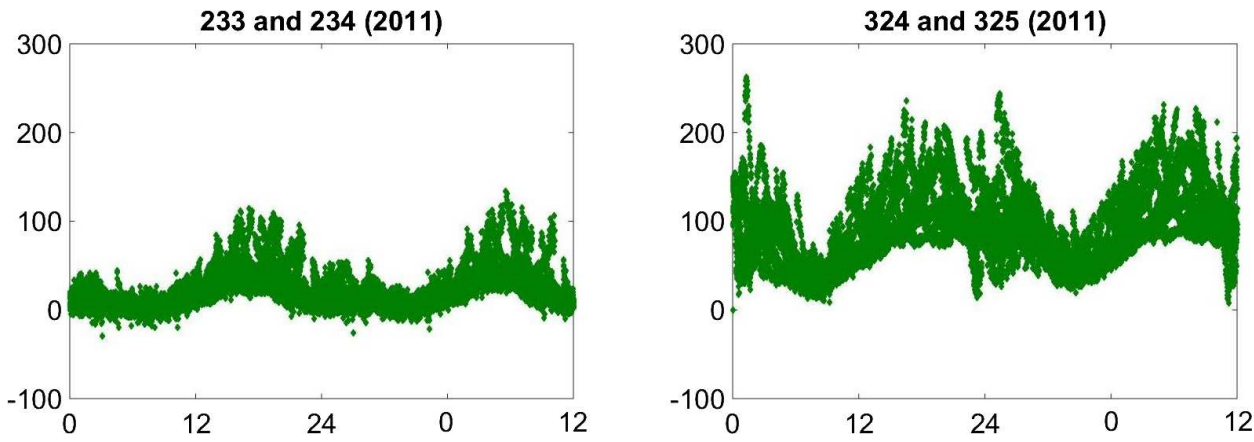

Fig. 6. Slant TEC distribution over the station PRU2. 


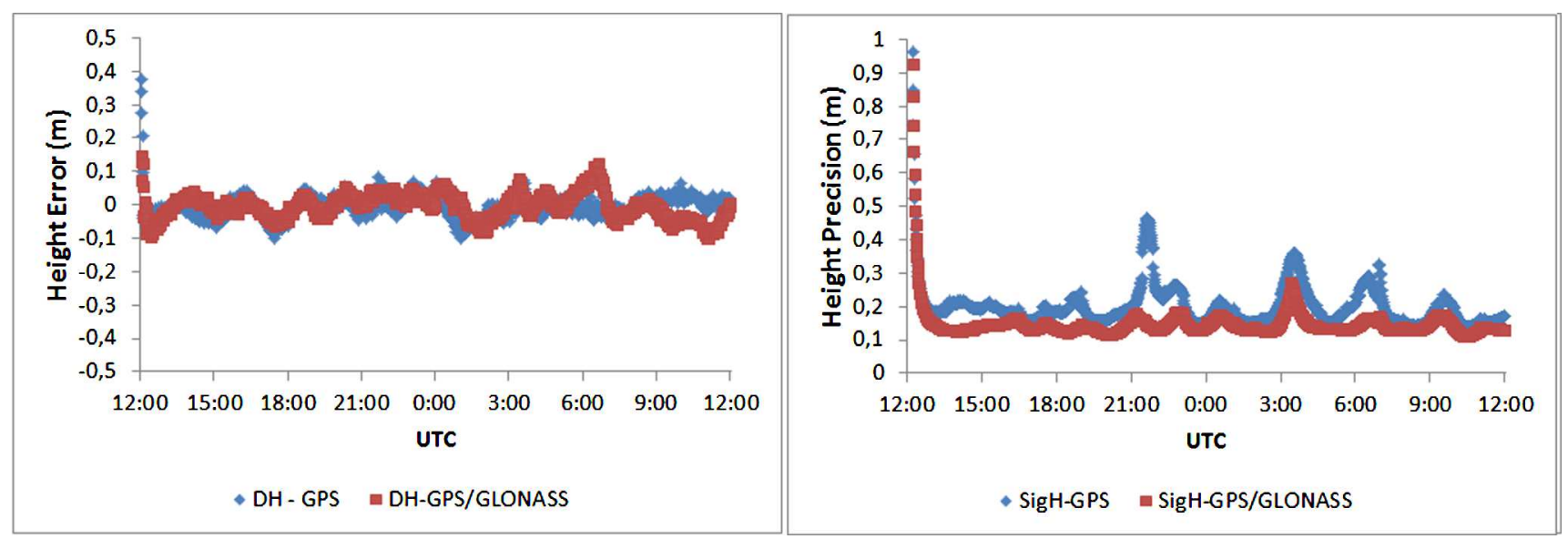

Fig. 7. Height error (left) and estimated height precision (right) for DoY 233-234 of 2011, station PRU2.

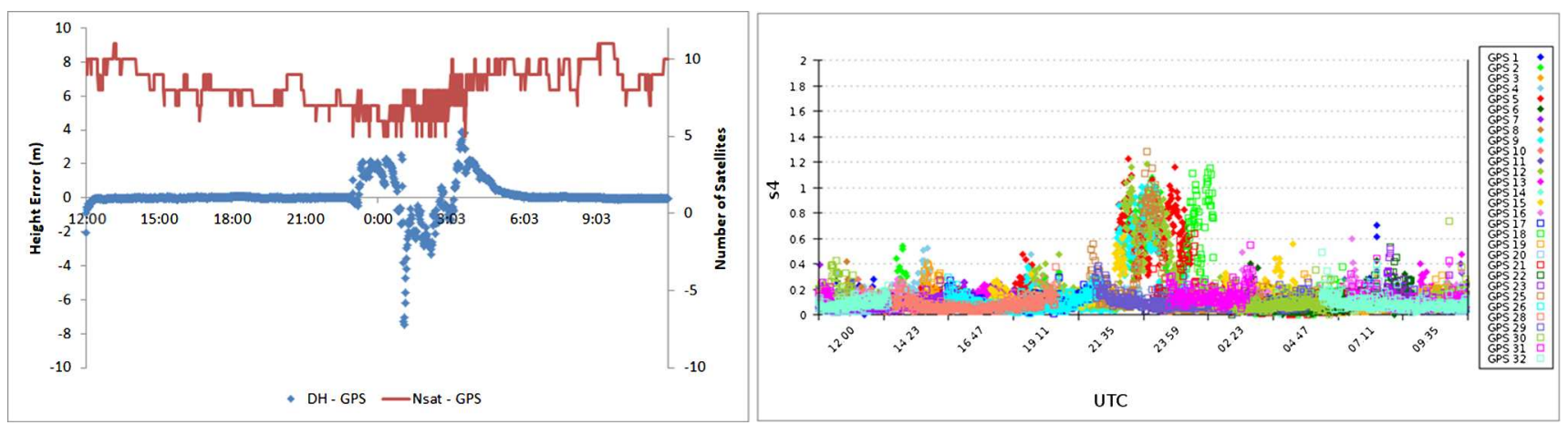

Fig. 8. Height error using only GPS data, number of satellites and S4 (DoY 324-325 of 2011).

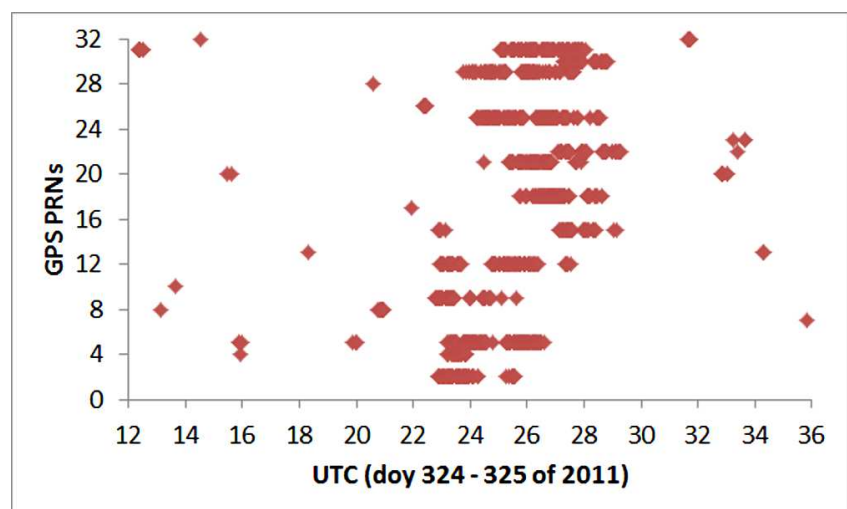

Fig. 9. Identification of GPS cycle slip per satellite at PRU2 (DoY 324-325 of 2011).

uncalibrated STEC does not account for the Interfrequency Bias (IFB) and therefore can assume negative values, but this is not relevant for the analysis of variations in the STEC. In Figure 6, strong variations, with values reaching peaks of up to 200 TECU on days 324 and 325 of 2011 are observed. The STEC from LPIM is estimated based on GNSS observables and accounts for the IFBs, which are estimated by the well

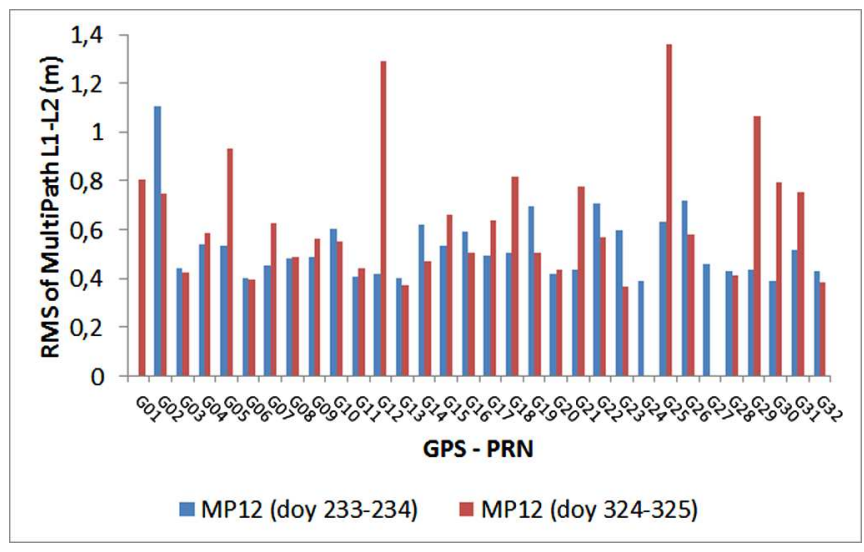

Fig. 10. RMS of multipath (entire day) at station PRU2.

known technique described inCiraolo et al. (2007), Brunini et al. (2008) and Brunini and Azpilicueta (2009, 2010).

As the error due to the ionosphere generally affects most significantly the vertical component in GNSS positioning, the accuracy (error against the established ground truth) of the estimated elipsoidal height $(h)$ has been chosen as the metric to carry out the analyses. These errors (either considering GPS or 

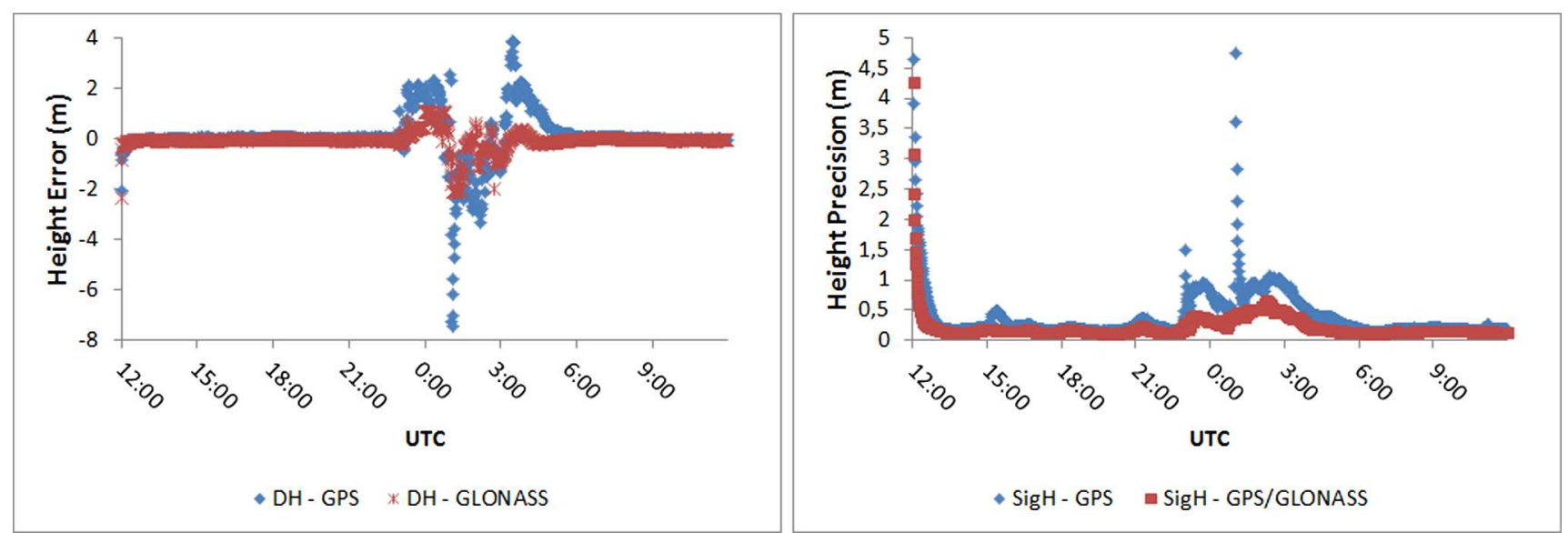

Fig. 11. Height error (left) and estimated height precision (right) for DoY 324-325 of 2011.

Table 2. RMS of height and improvements considering the entire period.

\begin{tabular}{llll}
\hline DoY of 2011 & GPS & GPS/GLONASS & Improvement (\%) \\
\hline 233-234 & 0.098 & 0.091 & 8 \\
$324-325$ & 0.947 & 0.354 & 63 \\
\hline
\end{tabular}

GPS/GLONASS data) for the PRU2 station on doy 233-234 of 2011 (weak scintillation effects) are shown in Figure 7 (DH), as well as the precision of the estimated height (SigH) considering the data processing starting and finishing at 12:00 UTC of each day.

The height error for PRU2 station on days 233-234 does not present significant differences between the solutions using GPS alone and GPS/GLONASS, considering that the scintillation levels on these days are weak (Fig. 3). Concerning the precision, the integrated GPS/GLONASS solution provides better precision for all epochs in the time series, as can be seen on the right hand side plot of Figure 7 . This is in agreement with what is expected when applying data from the GNSS integration.

The height error by using only GPS data on days 324-325 of 2011 (under strong scintillation levels) can be seen in Figure 8 together with the number of satellites in view and also the S4 per satellite.

As shown in Figure 8, during periods affected by strong scintillation, the number of GPS satellites available for positioning decreases considerably, with not enough data for position estimation at some epochs. Besides that, most satellites involved are affected by scintillation effects as can be seen in the plot of S4 per satellite. Such example illustrates the fact that taking the affected satellite $(s)$ out of the processing may not be the best strategy for kinematic positioning. The height error in this case reached a maximun of approximately $8 \mathrm{~m}$.

As shown in Figure 9, under such harsh scintillation conditions a large number of cycle slips, losses of lock and outliers due to scintillation effects are observed, what sometimes requires the ambiguity reinitialization in the recursive adjustment, causing jumps in the coordinates time series.

The cycle slip identification presented in Figure 9 was accomplished by using in-house software called "RT PPP" that applies a recursive filter with the wide-lane combination of GPS pseudorange and phase in L1 and L2 bands (Blewitt, 1990). It is possible to see in Figure 9 that most cycle slips occur during the period affected by strong ionosphere scintillation.

The RMS of multipath between L1 and L2 (MP12) observables, computed for the data being analysed (DoY 233234 and 324-325 of 2011) using the teqc software, is shown in Figure 10. This software applies the equations described in Estey \& Meertens (1999).

As seen in Figure 10, the level of multipath is amplified for most of satellites in on DoY 324-325 of 2011 what is probably correlated with the ionosphere conditions (Figs. 5 and 6) and scintillation effects (Fig. 3) (Zheng et al., 2012; Chen et al., 2016). In such cases the RMS daily mean of MP12 was $0.523 \mathrm{~m}$ and $0.641 \mathrm{~m}$, respectively, for the pairs DoY 233-234 and 324-325 of 2011.

The height error and precision for days 324-325 of 2011 for the PRU2 station considering the integration of GPS and GLONASS are shown in Figure 11.

From Figure 11 it is possible to see that the integration of GPS/GLONASS data provided better results when compared to GPS data alone. The RMS for the estimated height component was computed considering respectively the differences between estimation with GPS only and with GPS/GLONASS integration. Results are presented in Table 2 together with the improvements achieved by the integration, considering the entire period of data processing $(24 \mathrm{~h})$.

For the days with weak scintillation, the improvement when using integrated GPS/GLONASS instead of GPS only reaches the order of $8 \%$. However, for the days with strong scintillation the improvement reaches the order of $63 \%$, with RMS of $0.947 \mathrm{~m}$ for PPP with GPS only and $0.354 \mathrm{~m}$ with GPS/GLONASS. Considering only the period most affected on days 324-325 of 2011, i.e. the period from 23:00 UTC of day 324 until 06:00 UTC of day 325, the RMS was $1.749 \mathrm{~m}$ for GPS alone and $0.656 \mathrm{~m}$ for GPS/GLONASS, respectively, also showing an improvement of approximately $63 \%$. 
GPS

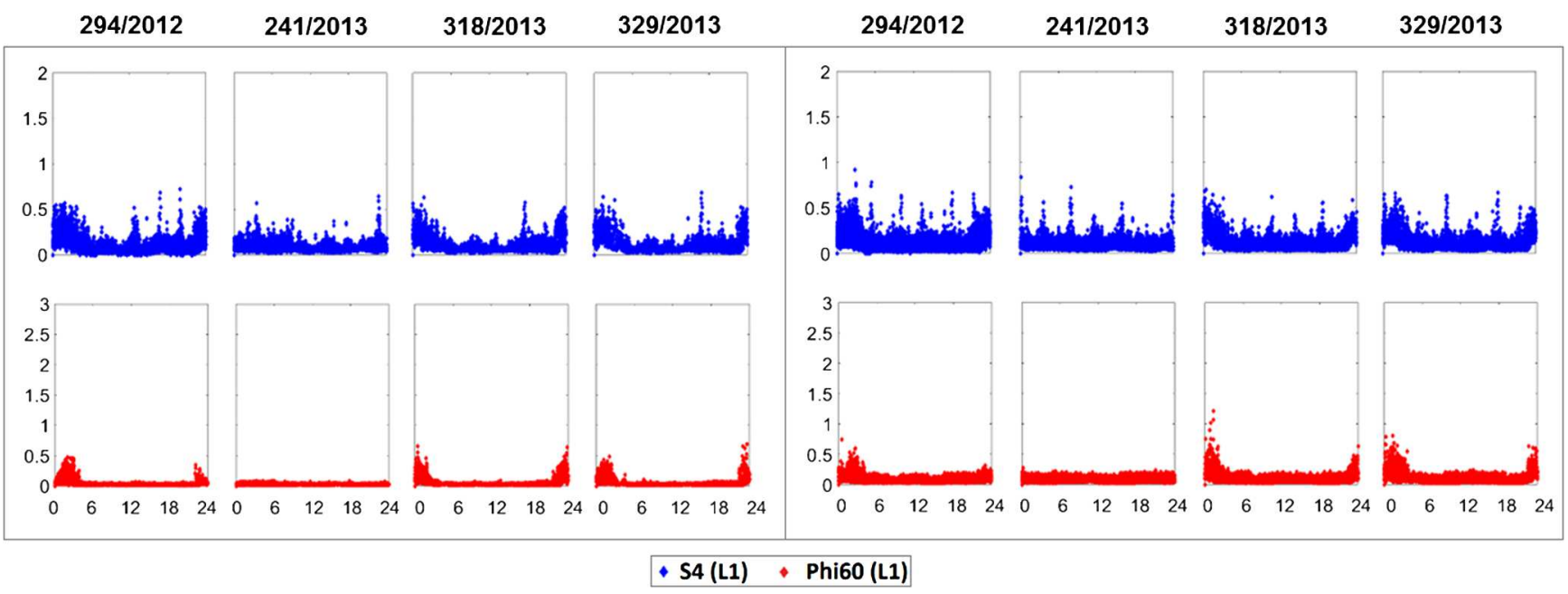

Fig. 12. S4 and Phi60 for the L1 frequency for station PALM.

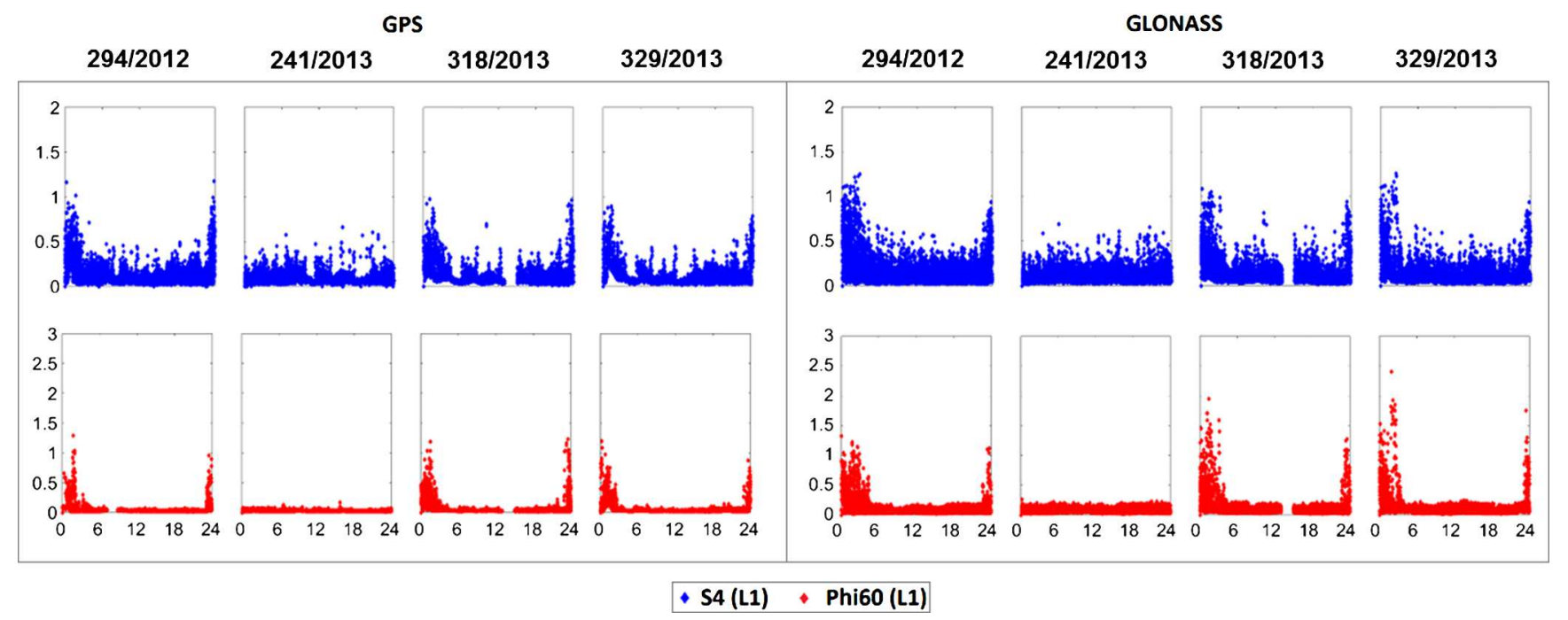

Fig. 13. S4 and Phi60 for the L1 frequency for station PRU1.

Other days during the years 2012 and 2013 with data under weak and moderate to strong ionospheric scintillation effects were also analyzed. The chosen days are: 20/10/2012 (DoY 294 of 2012), 29/08/2013 (DoY 241 of 2013), 14/11/2013 (DoY 318 of 2013) and 25/11/2013 (DoY 329 of 2013). Figures 12 and 13 show the S4 and Phi60 values (L1 frequency for GPS and GLONASS) observed respectively at stations PALM and PRU1 for the specific days.

Analyzing the S4 and Phi60 values shown in Figure 12 it is possible to see that in all cases for the station PALM the ionospheric scintillation effects can be classified as weak to moderate $(\mathrm{S} 4<1$ and Phi60 $<0.8$ ) according to Table 1. However, for station PRU1, as shown in Figure 13, only on DoY 241 in $2013(29 / 08 / 2013)$ can the ionospheric scintillation activity be classified as weak to moderate and for the remaining days it can be classified as moderate to strong, with
S4 reaching values greater than 1 . It is also possible to see in Figures 12 and 13 that the GLONASS signal is more susceptible to ionosphere scintillation effects than GPS, with Phi60 reaching values greater than 0.8 .

All data collected at stations PALM and PRU1 were processed in kinematic mode PPP, both using GPS only and GPS/GLONASS data. The time series of the estimated height precision can be seen in Figures 14 and 15, respectively, for stations PALM and PRU1.

As expected, it can be seen in Figures 14 and 15 that the estimated precision when processing GPS/GLONASS data is consistently better than when applying only GPS data. Such outcome is expected since the number of satellites increases considerably (from an average of 8 to approximately 15) when adding the GLONASS constellation, consequently improving the geometry (DOP). The precision time series for PRU1 on 


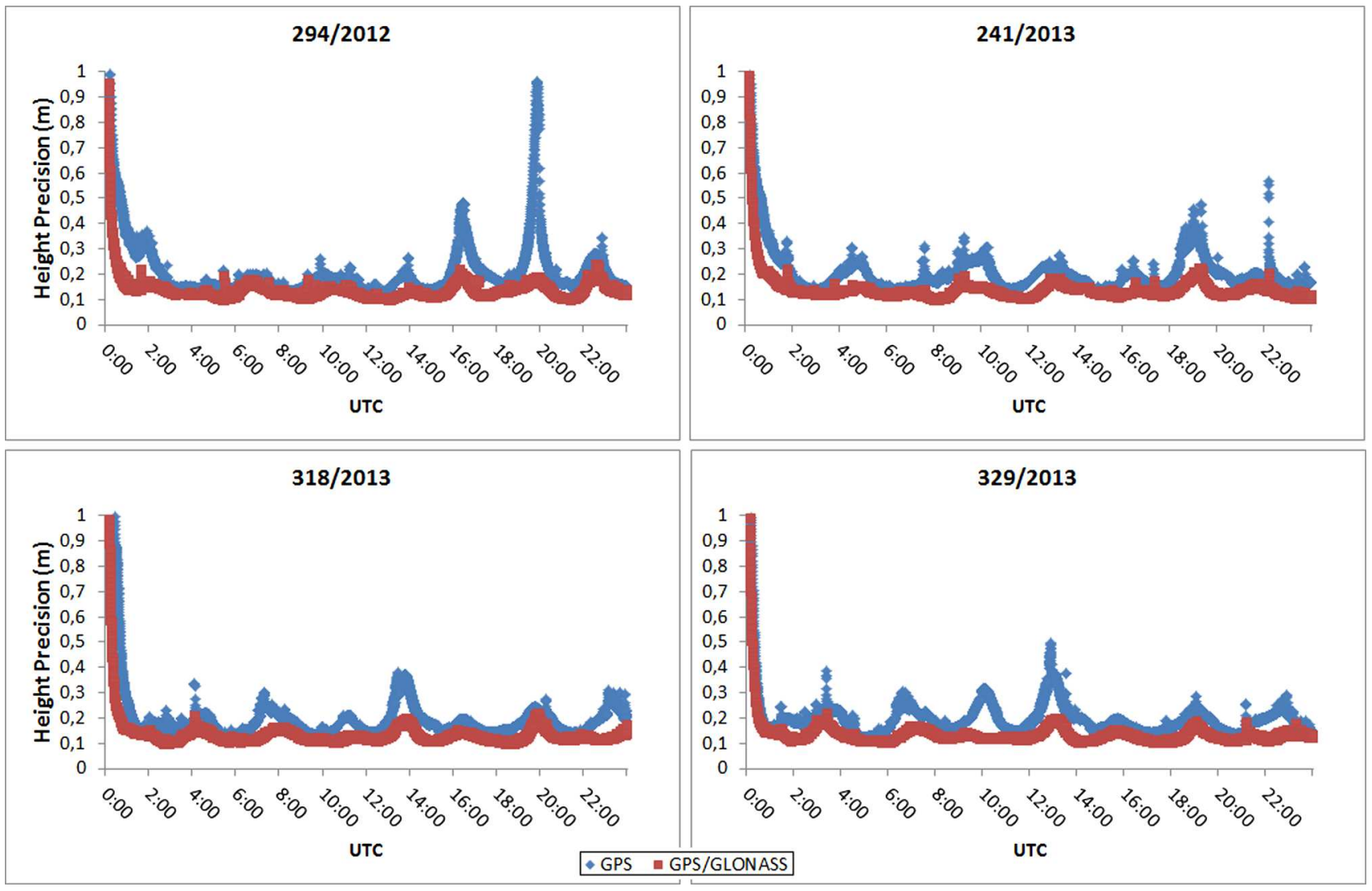

Fig. 14. Estimated height precision for PALM station.

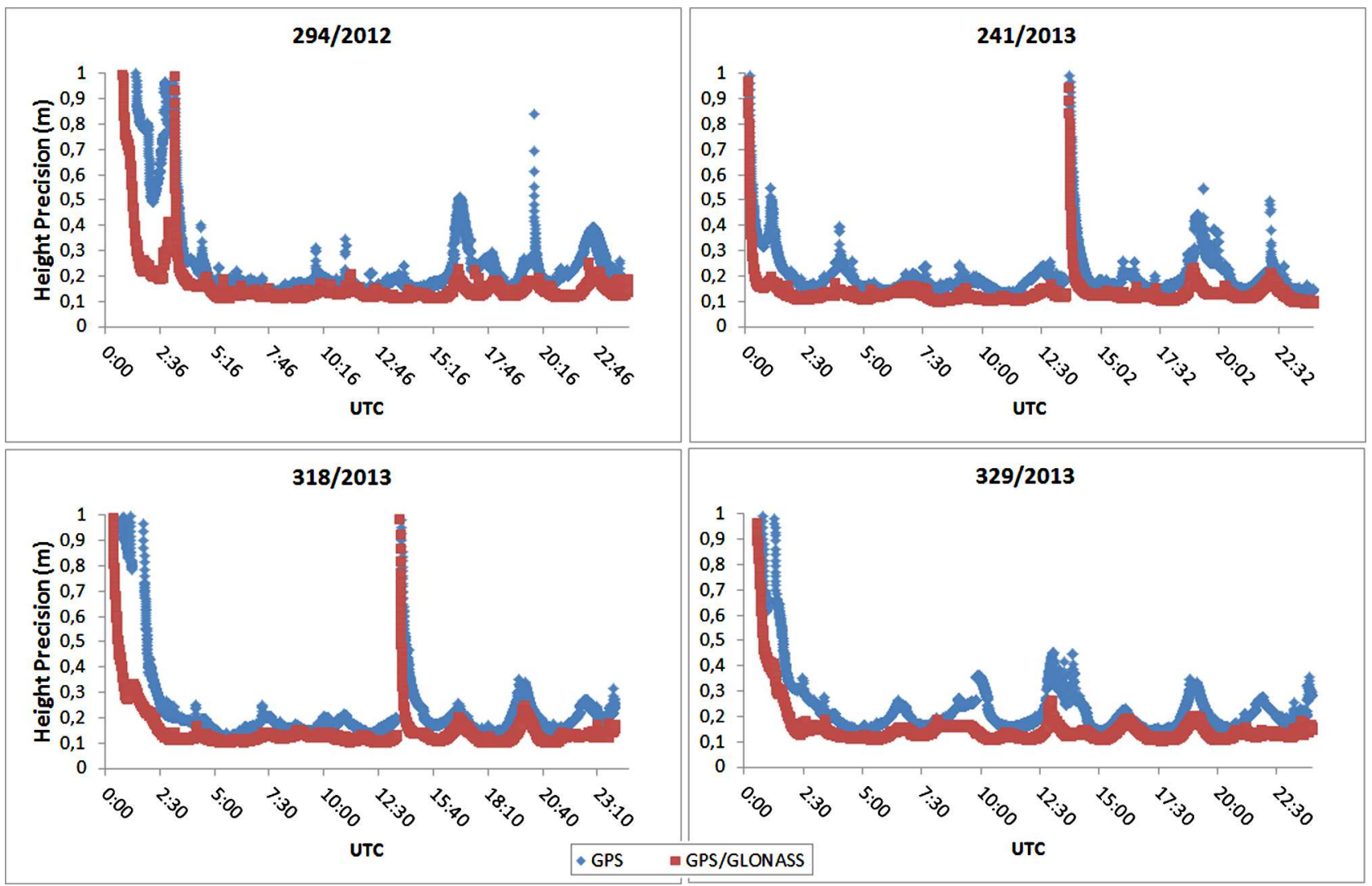

Fig. 15. Estimated height precision for PRU1 station. 


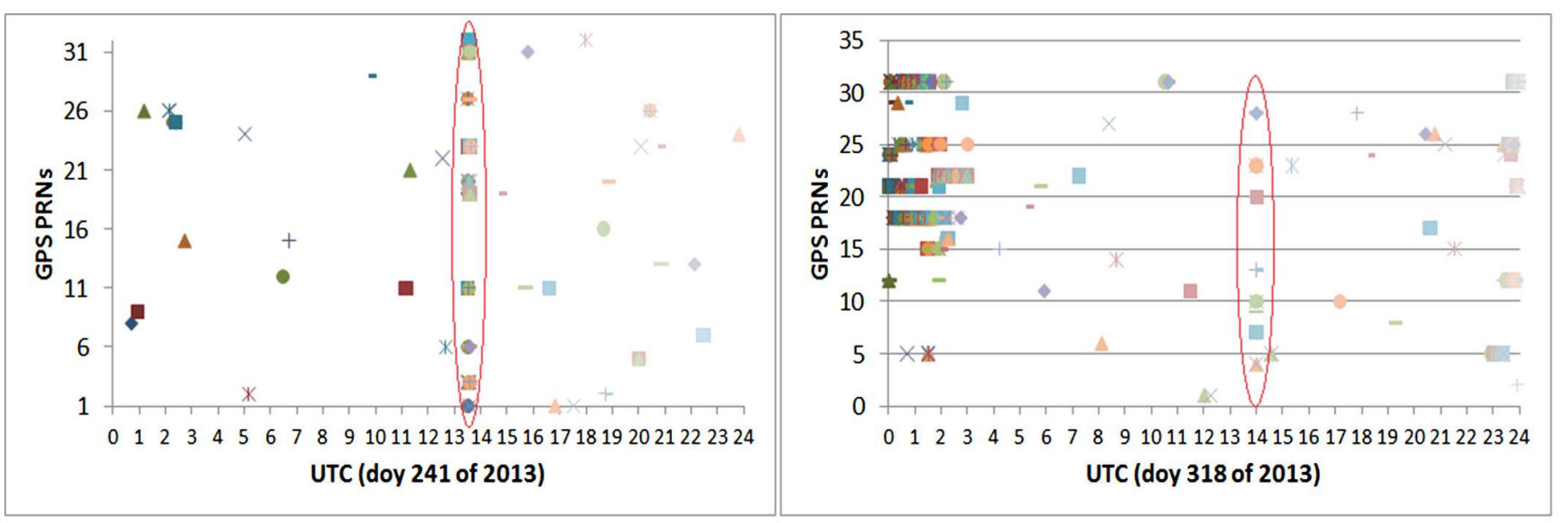

Fig. 16. Detected cycle slips for PRU1 station in the DoY 241 and 318 of 2013.

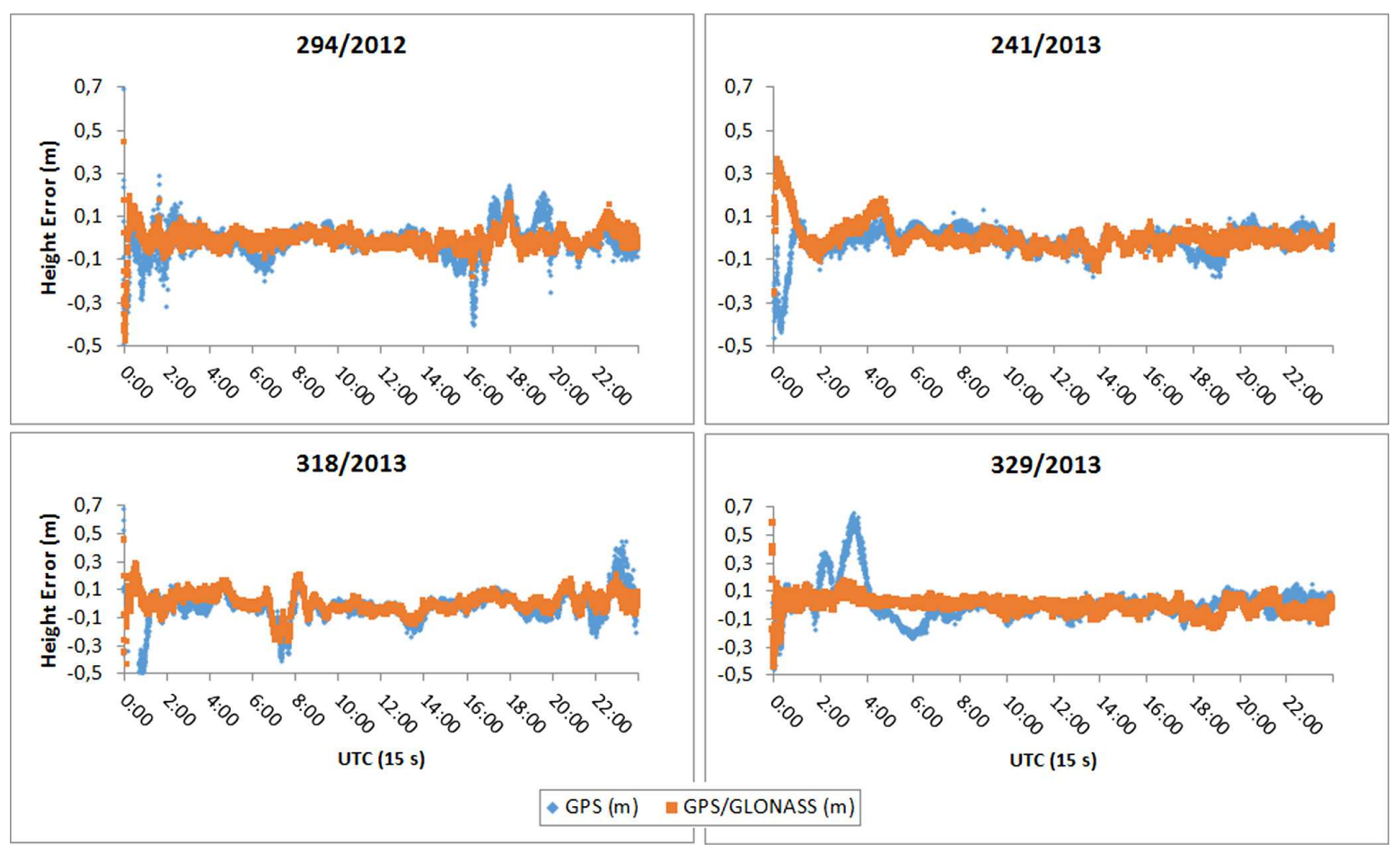

Fig. 17. Height errors for PALM station.

DoY 241 and 318 present peaks of initialization near the epochs 13:30 UTC and 14:00 UTC respectively, as can be observed in Figure 15. Such peaks occurred due to cycle slips on several satellites, detected at the cited epochs, as highlighted (red ellipses) in Figure 16.

The comparison of the estimated height with the established ground truth is presented in Figures 17 and 18 for PALM and PRU1 stations respectively.

Analyzing the errors in the estimated height, improvement can be seen when applying GPS/GLONASS compared to GPS alone, in particular during periods of scintillation occurrence, around the first six hours and near 24:00 UTC. Table 3 presents the RMS in the East, North and Up components in the Local Geodetic System and also the resulting 3D errors and corresponding improvements considering the entire period (24 h) of data involved in the processing.

The improvement in the 3D error (Table 3) for station PALM (weak to moderate scintillation) ranges from approximately $7 \%$ up to $34 \%$, while for PRU1 (moderate to strong scintillation) it ranges from approximately $11 \%$ up to $57 \%$, considering the entire period $(24 \mathrm{~h})$ of data processing. The ionospheric scintillation conditions are shown in Figures 12 and 13, where for station PALM scintillation levels are classified as weak to moderate and for PRU1 as moderate to strong. The improvement when applying GPS/GLONASS as opposed to GPS alone in the PPP solution can be more clearly noticed in the height component (Up), whereas for the horizontal component on some of the days there is no 


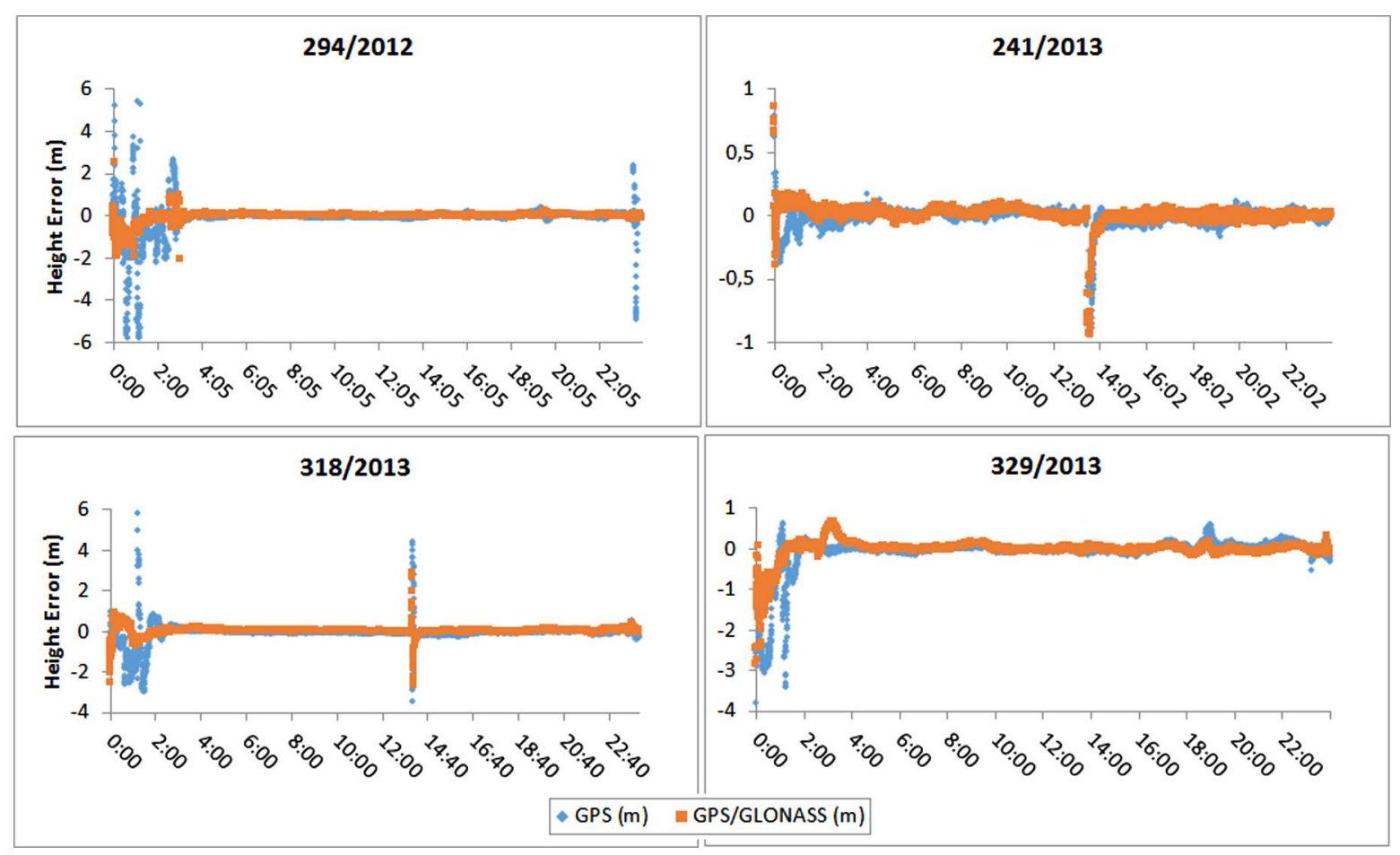

Fig. 18. Height errors for PRU1 station.

Table 3. RMS of the kinematic PPP and improvements.

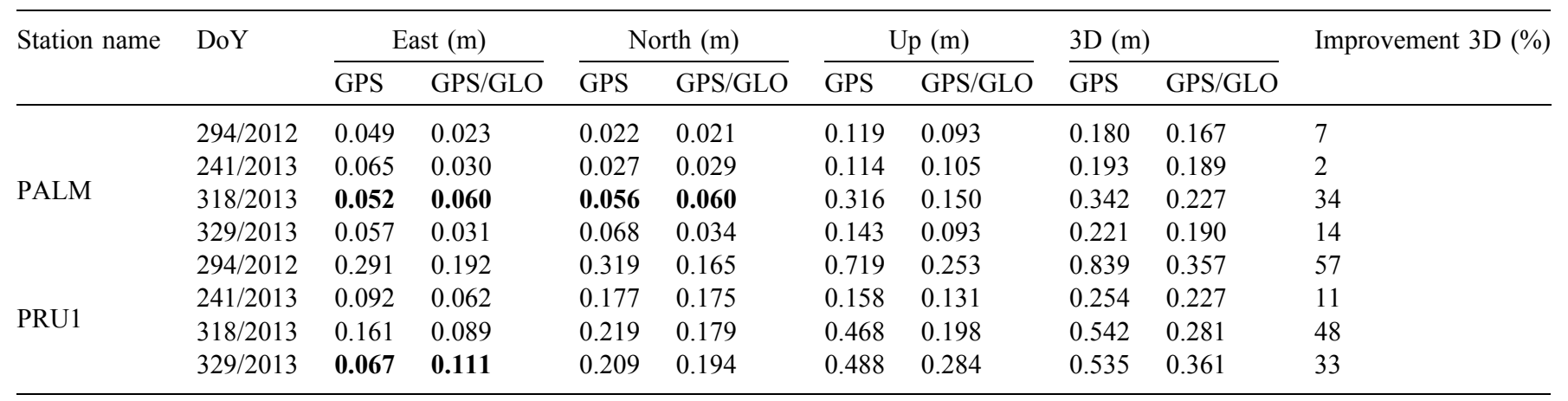

improvement, such as for example on days 318/2013 for station PALM and 329/2013 for PRU1. Therefore, it is plausible to conclude that the level of improvement is greater for moderate to strong scintillation conditions, such as observed at station PRU1 where the maximum improvement reached approximately $57 \%$ on day 294 of 2012 .

\section{Conclusions}

The occurrence of ionospheric scintillation on GNSS signals is intense in the geomagnetic high latitudes and equatorial regions. The Brazilian territory is considerably affected, where scintillation occurrence is associated with the crests of the equatorial anomaly. An analysis of the impact of ionospheric scintillation effects on GPS and GLONASS signals was presented, along with accuracy assessment in kinematic PPP processing. The ionospheric scintillation conditions were characterized by the widely recognized amplitude and phase scintillation indices, respectively S4 and $\sigma_{\varphi}$.

The mathematical model involved in PPP with GPS/ GLONASS integration was described in detail and PPP accuracy analyses were carried out aiming to compare the use of GPS data alone with integrated GPS and GLONASS data, under ionospheric scintillation conditions. PPP processing in kinematic mode was used for the analyses, as this technique is strongly influenced by the effects of ionospheric scintillation.

The experiments exploited GNSS data collected by the CIGALA/CALIBRA network, which is equipped with specialized ISMR receivers capable to provide not only GNSS data but also the $\mathrm{S} 4$ and $\sigma_{\varphi}$ indices, among other parameters. 
The data collected at station PRU1 on DoY 324-325 of 2011 experienced strong scintillation effects for at least 6 hours starting near 23:00 UTC of DoY 324 until 06:00 UTC of DoY 325 . During this period the $\mathrm{S} 4$ and $\sigma_{\varphi}$ indices reached values of approximately 1.5 (Fig. 3) and STEC reached the order of 200 TECU (Fig. 6).

The estimated coordinates' time series in kinematic PPP mode presented peaks of approximately $8 \mathrm{~m}$ when using GPS data alone (Fig. 8). These peaks occur mainly due to losses of signal lock and cycle slips, which cause the ambiguity parameter reinitialization in the recursive adjustment. However when adding GLONASS data (Fig. 11) considerable improvement was observed, especially in the accuracy of the height component, which reached the order of $63 \%$ in RMS (Table 2).

The GNSS data at station PRU1 on DoY 233-234 of 2011, classified as a period of weak to moderate scintillation (Fig. 3), observed improvement in height accuracy up to the order of $8 \%$ when adding GLONASS data in kinematic PPP processing (Table 2).

Other days during the years 2012 and 2013, characterized as days of weak and moderate to strong ionospheric scintillation levels, were also analyzed. It was noticed that the GLONASS signals seem to be more susceptible to ionospheric scintillation effects than the GPS signals (Figs. 12 and 13), what can be related with the structure or the power of the GLONASS signals.

The estimated precision achieved in kinematic PPP was shown to be consistently better when integrating GPS and GLONASS data, as opposed to using GPS data alone - this is seen in Figures 14 and 15, what is already expected since there are more GNSS data available for positioning. The accuracy improvement in positioning is greater for cases where scintillation levels are moderate to strong, with improvements in the $3 \mathrm{D}$ error for PALM (weak to moderate scintillation) reaching up to $34 \%$ and for PRU1 (moderate to strong scintillation) reaching up to $57 \%$, considering the entire period $(24 \mathrm{~h})$ of data processing (Table 3 ).

In conclusion, based on the analyses carried out in this study, it is possible to infer that using multi-constellation GNSS data can improve positioning accuracy under ionospheric scintillation conditions, in particular when they are moderate to severe.

Acknowledgments. The authors thank the Brazilian Council of Research and Development (CNPq) for financial support through the processes 475775/2013-9; 448488/2014-0 and $311545 / 2015-7$. The data used in the experiments subject of this study is part of the CIGALA and CALIBRA projects funded by the European Commission Seventh Framework Program (FP7) and carried out in the context of the Galileo FP7 R\&D program supervised by the European GNSS Agency (GSA).

The editor thanks Jacek Paziewski and two anonymous referees for their assistance in evaluating this paper.

\section{References}

Aquino M, Andreotti M, Dodson AH, Strangeways H. 2007. On the use of ionospheric scintillation indices as input to receiver tracking models. Adv Space Res 40: 426-435, DOI:10.1016/j. asr.2007.05.035.

Aquino M, Monico JFG, Dodson AH, Marques HA, Franceschi G, Alfonsi L, Romano V, Andreotti M. 2009. Improving the GNSS positioning stochastic model in the presence of ionospheric scintillation. $J$ Geod 83: 953-966, DOI:10.1007/ s00190-009-0313-6.

Bassiri S, Hajj GA. 1993. Higher-order ionospheric effects on the global positioning systems observables and means of modeling them. Manuscr Geod 18: 280-289.

Basu S, Groves KM, Specification and forecasting of outages on satellite communication and navigation systems, Space Weather, Geophysical Monograph, American Geophysical Union, Washington, DC, 2001, vol. 125, pp. 424-430, DOI:10.1029/ GM125p0423

Blewitt G. 1990. An automated editing algorithm for GPS data. Geophys Res Lett 17: 199-202.

Brunini C, Azpilicueta F. 2009. Accuracy assessment of the GPSbased slant Total Electron Content (sTEC). J Geod 83: 773-785, DOI:10.1007/s00190-008-0296-8.

Brunini C, Azpilicueta F. 2010. GPS slant total electron content accuracy using the single layer model under different geomagnetic regions and ionospheric conditions. J Geod 84: 293-304, DOI:10.1007/s00190-010-0367-5.

Brunini C, Meza A, Gende M, Azpilicueta F. 2008. South American regional ionospheric maps computed by GESA: A pilot service in the framework of SIRGAS. In: Advances in Space Research, Elsevier Ltd, 42, pp. 737-744, DOI:10.1016/j.asr.2007.08.041.

Cai C, Gao Y. 2007. Precise Point Positioning using combined GPS and GLONASS observations. J Glob Position Syst 6: 13-22.

Cai C, Gao Y. 2013. Modeling and assessment of combined GPS/ GLONASS Precise Point Positioning. GPS Solut 17: 223-236, DOI:10.1007/s10291-012-0273-9.

Chen D, Ye S, Xia J, Liu Y, Xia P. 2016. A geometry-free and ionosphere-free multipath mitigation method for BDS threefrequency ambiguity resolution. $J$ Geod 90: 703-714, DOI:10.1007/s00190-016-0903-z.

Ciraolo L, Azpilicueta F, Brunini C, Meza A, Radicela S.M. 2007. Calibration errors on experimental slant total electron content determined with GPS. J Geod 81: 111-120, DOI:10.1007/ s00190-006-0093-1.

Collins P, Bisnath S, Francois L, Pierre H. 2008. Undifferenced GPS ambiguity resolution using the decoupled clock model and ambiguity datum fixing. J Inst Navig 57: 123-135.

Conker RS, El-Arini B, Hegarty CJ, Hsiao T. 2003. Modeling the effects of ionospheric scintillation on GPS/Satellite-Based augmentation system availability. Radio Sci 38: 1-1-1-23, DOI: 10.1029/2000RS002604.

Davies K. Ionospheric radio, Short Run Press LTd., ISBN: 978$0863411861,1990$.

De Paula ER, Kherani EA, Abdu MA, Batista IS, Sobral JHA, et al. 2007. Characteristics of the ionospheric irregularities over Brazilian longitudinal sector. Indian J Radio Space Phys 36: 268-277

Donahue B, Wentzel J, Berg R. 2015. Guidelines for RTK/RTN GNSS surveying in Canada. Version 1.2. Available at: http://www. nrcan.gc.ca/sites/www.nrcan.gc.ca/files/earthsciences/pdf/Canada \%20RTK_UserGuide_v1_2-EN.pdf. Accessed in July 2017.

Estey LH, Meertens CM. 1999. TEQC: the multi-purpose toolkit for GPS/GLONASS data. GPS Solut 3: 42-49, DOI:10.1007/ PL00012778.

Fritsche M, Dietrich R, Knöfel C, Rülke A, Vey S, Rotacher M, Steigenberger P. 2005. Impact of higher-order ionospheric terms on 
GPS estimates. Geophys Res Lett 32: L23311, DOI:10.29/ 2005GL024342.

Ge M, Gendt G, Dick G, Zhang FP. 2005. Improving carrier-phase ambiguity resolution in global GPS network solutions. J Geod 79: 103-110.

Geng J, Meng X, Dodson A, Teferle F. 2010. Integer ambiguity resolution in Precise Point Positioning: method comparison. $J$ Geod 84: 569-581, DOI:10.1007/s00190-010-0399-x

GLONASS, 2016. GLONASS Status. Federal Space Agency. Information-Analycal Centre 2016. Available at http://glonassiac.ru/en/GLONASS/index.php. Acessed in 2017.

Hernandes-Pajares M, Juan JM, Sanz J, Orús R. Second-order ionospheric term in GPS: Implementation and impact on geodetic estimates, J Geophys Res 112: B08417, DOI:10.1029/ 2006JB004707, 2007.

Hofmann-Wellenhof B, Lichtenegger H, Wasle E, GNSS-Global Navigation Satellite Systems: GPS, GLONASS, Galileo and more, Springer-Verlag, New York, ISBN: 978-3-211-73012-6, 2008.

Hoque MM, Jakowski N. 2007. Higher order ionospheric effects in precise GNSS positioning. J Geod 81: 259-268.

ICD-GLONASS, 2008. Global Navigation Satellite System GLONASS interface control document: navigational radio signal in bands L1, L2, version 5.1, Moscow, .

Kedar S, Hajj A, Wilson BD, Heflin MB. 2003. The effect of the second order GPS ionospheric correction on receiver positions. Geophys Res Lett 30: 1829

Kelley MC, The earth's ionosphere: plasma physics and electrodynamics, Academic Press, San Diego, CA, 1989.

Klobuchar JA. 1976. Ionospheric Time delay corrections for advanced satellite ranging systems, NATO AGARD Conference, Proceedings 209. In: Propagation Limitations of Navigation and Positioning Systems. Paris: NATO AGARD.

Laurichesse D, Mercier F, Berthias JP, Broca P, Cerri L. 2009. Integer ambiguity resolution on undifferenced GPS phase measurements and its application to PPP and satellite precise orbit determination. J Inst Navig 56: 135-149.

Leick A, GPS satellite surveying, John Wiley and Sons, New York, ISBN: 0-471-05930-7 2004.

Li X, Zhang X, Ren X, Fritsche M, Wickert J, Schuh H. 2015. Precise positioning with current multi-constellation Global Navigation Satellite Systems: GPS, GLONASS, Galileo and BeiDou. Sci Rep 5, DOI:10.1038/srep08328.

Marques HA, Monico JFG, Aquino M. 2011. RINEX HO: secondand third-order ionospheric corrections for RINEX observation files. GPS Solut 15: 305-314.

Marques HAS, Monico JFG, Marques HA. 2016. Performance of the L2C civil GPS signal under various ionospheric scintillation effects. GPS Solut 20: 139-149, DOI:10.1007/ s10291-015-0472-2.

Oleynik E. 2012. GLONASS: status and modernization. In: Proceedings of United Nations International Meeting on the
Applications of Global Navigation Satellite Systems. Riga, Lativia. Available at http://www.unoosa.org/documents/pdf/psa/activities/ 2012/un-latvia/ppt/1-2.pdf Accessed in 2017.

Petit G, Luzum B. 2010. IERS Conventions (2010). IERS Convention Centre. Bureau International des Poids et Mesures (BIPM) and US Naval Observatory (USNO.

Seeber G. Satellite geodesy: foundations, methods, and applications, 2nd edn., Walter de Gruyter, Berlin, New York, ISBN: 3-11-017549-5, 2003.

Silva HA, Camargo PO, Monico JFG, Aquino M, Marques HA, De Franceschi G, Dodson A. 2010. Stochastic modelling considering ionospheric scintillation effects on GNSS relative and point positioning. Adv Space Res 45: 1113-1121, DOI:10.1016/j. asr.2009.10.009.

Teunissen PJG, Khodabandeh A. 2015. Review and principles of PPP-RTK methods. J Geod 89: 217-240, DOI:https://doi.org/ $10.1007 / \mathrm{s} 0019$.

Tiwari R, Skone S, Tiwari S, Strangeways HJ. 2011. 3WBMod assisted PLL GPS software receiver for mitigating scintillation affect in high latitude region. IEEE, Available at http://www.ursi. org/proceedings/procGA11/ursi/FG-4.pdf.

Van Dierendonck AJ. 2001. Measuring ionospheric scintillation effects from GPS signals. In: ION 59th Annual Meeting. Albuquerque, New Mexico, pp. 391-396.

Van Dierendonck AJ, Klobuchar J, Hua Q. 1993. Ionospheric scintillation monitoring using commercial single frequency $\mathrm{C} / \mathrm{A}$ code receivers. In: Proceedings of the 6th international technical meeting of the satellite division of the Institute of Navigation (ION GPS-93). Arlington, VA, pp. 1333-1342.

Vani BC, Shimabukuro MH, Monico JFG. 2016. Visual exploration and analysis of ionospheric scintillation monitoring data: the ISMR query tool. Comput Geosci 104: 125-134, Available at http://dx. doi.org/10.1016/j.cageo.2016.08.022 Accessed 2017.

Wanninger L. 2011. Carrier-phase inter-frequency biases of GLONASS receivers. $J$ Geod 86: 139-148, DOI:10.1007/ s00190-011-0502-y.

Xu R, Liu Z, Li M, Morton Y, Chen W. 2012. An analysis of lowlatitude ionospheric scintillation and its effects on Precise Point Positioning. J Glob Position Syst 11: 22-32, DOI:10.5081/ jgps.11.1.22.

Zhang X, Guo F, Zhou P. 2014. Improved Precise Point Positioning in the presence of ionospheric scintillation. GPS Solut 18: 51-60.

Zheng K, Zhao W, Pang S, Yang Y, Wan S. Study on Mitigation of Multipath Effect in Real-Time Kinematic PPP with a Single Shipborne GNSS Receiver. In: Sun J, Liu J, Yang Y, Fan S. (eds.) China Satellite Navigation Conference (CSNC) 2012 Proceedings. Berlin, Heidelberg: Lecture Notes in Electrical Engineering, Springer, pp. 161, 2012. DOI:10.1007/978-3-642-29193-7_66.

Zhimin L, Li Y, Guo J, Li F. 2016. Influence of higher-order ionospheric delay correction on GPS precise orbit determination and precise positioning. Geod Geodyn 7: 369-376, ISSN 1674-9847.2016.

Cite this article as: Marques HA, Marques HAS, Aquino M, Veettil SV, Monico JFG. 2018. Accuracy assessment of Precise Point Positioning with multi-constellation GNSS data under ionospheric scintillation effects. J. Space Weather Space Clim. 8: A15 